\title{
Research on the Development and Innovation of Architectural Engineering Management Education in China under the Background of New Times
}

\author{
Dai Xiaoli \\ Xi’an Siyuan University, Shaanxi, China, 710038
}

Keywords: construction engineering; safety supervision; existing problems; optimization suggestions

\begin{abstract}
Construction engineering is a complex and systematic project. It requires multiple projects to work together. The mobility of construction site personnel is relatively large. In order to ensure the safe and orderly construction of the project, it is necessary to provide safety supervision and management education for the current project. The scientific and rational analysis is conducted on the problems existing in the scientific analysis and the use of scientific methods to deal with such issues, further intensify safety supervision and management education, and implement safety production step by step to each operation position and increase safety. Hidden trouble investigation and timely rectification of these problems, through the implementation of education and training, regulate the construction operations of front-line personnel.
\end{abstract}

\section{Introduction}

Some security management and education personnel have the psychological "over and over" mentality in most of their normal work. The responsibility for security cannot be put in place, directly reducing the role and efficiency of safety supervision work, and causing some disease sites, quality problems, and hidden dangers to be prevented from being promptly Discovery and remediation ultimately led to security incidents.

\section{Problems in Construction Engineering Safety Supervision and Management Education in the New Times}

\subsection{The incomplete current construction safety management education system}

Many construction projects in China have been affected by the lack of safety consciousness of the leaders of the participating companies, and they cannot be combined with the actual characteristics of the construction projects of the participating companies. They have not been able to build systems and a sound construction safety management education system according to requirements. The result of this status quo is that the construction site safety supervision and management education cannot be truly implemented at all levels of management education and in various production positions [1].

\subsection{The poor safety consciousness of management education personnel and construction workers}

In the construction process, human factors have a very significant impact on the safety of construction projects. Therefore, it is necessary to ensure that first-line construction workers have a high enough awareness of safe construction, so as to ensure the quality of construction projects while ensuring the construction process. There is no security issue. However, as far as the current situation is concerned, the front-line construction workers do not have a strong sense of safety protection. The first is that the first-line construction workers do not realize the importance of maintaining construction safety; second, when front-line construction workers use various types of construction machinery to perform work, because of their weak risk awareness, they will violate the convenience of the moment. The prescribed procedures are used for construction operations. 
Thirdly, in the construction project management education staff, the practitioners' awareness is not high. They are used to seeing strange things and cannot correct them promptly. During the construction process, safety management educators are the specific implementers who ensure the safety of the project construction. If these safety management educators cannot have a sufficiently high safety awareness and vigilance, they must not guarantee the safety of construction workers [2].Building management control form as shown below.

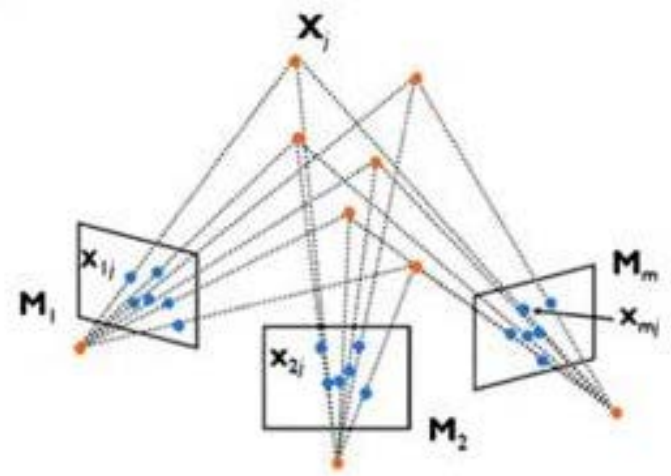

Recover position of $3 \mathrm{D}$ points $\left(\mathrm{X}_{\mathrm{i}}\right)$ and camera matrices* $\left(\mathrm{M}_{1}, \ldots, \mathrm{M}_{\mathrm{m}}\right)$

using correspondences between feature points in the images $\left(\mathrm{x}_{1 j}, \ldots \mathrm{x}_{\mathrm{mj}}\right)$

Fig.1 Building management control form

\subsection{Insufficient supervision work}

In the context of the new era, the supervision market has not yet fully entered the role of correct positioning, and supervisory personnel's various management education responsibilities cannot be fully implemented. Coupled with the continuous increase in the economic level of our country, the market is constantly expanding. Under the influence of various reasons, open competition has become a necessary situation in the current supervision industry, but the relevant departments in some places have used supervision. Enterprises must register and file regulations in the local area and intend to protect regional and subordinate supervision companies, which has led to the restriction of the development of supervision enterprises. The supervision industry can be said to be a new industry that has emerged in the new era. However, the quality of some personnel is not high enough to be able to perform their duties. Although young workers have some theoretical knowledge but lack practical experience, they cannot solve problems when they encounter problems. However, some experienced staff do not have the ability to innovate. Such phenomena are widespread, and they have also greatly constrained the development of the supervision industry, which is very unfavorable to the construction of the project.

\section{Optimize and Strengthen the Recommendations of Safety Supervision and Management Education}

\subsection{Establish and improve the safety management education system}

In accordance with the relevant provisions of national laws and regulations, it is necessary and effective to establish a set of sound standards for safety management education. To implement specific measures, it is necessary to: Define and refine the scope of responsibility for safety management education, and prevent duties. The scope of cross-cutting and unsupervised problems also require ensuring the implementation of responsibilities to individuals and raising awareness of crisis; strengthening the execution and action of safety management education, and gradually establishing a high-quality and efficient security service management education guarantee mechanism for the construction of buildings. Workers and practitioners must supervise and protect; establish detailed and effective safety regulations and regulations for management and education, and ensure that all aspects of construction are carried out in accordance with regulations[3].The safety education system's scoring formula is as follows. 


$$
e_{j}=-k \sum_{i=1}^{m} p_{i j} \times \ln p_{i j}
$$

\subsection{Strengthen construction safety protection measures}

Safety protection measures for construction projects are personal safety guarantees for construction workers. Therefore, the construction unit should actively strengthen the construction safety protection measures. The construction of safety protection measures for buildings must first of all increase the awareness of construction workers in safety construction. The hardware measures for building construction safety protection can only provide temporary protection to construction workers. The safety problems in building construction require construction workers to pay sufficient attention to them, while management and education personnel actively enhance the way through training and education. The level of construction work personnel's safety construction, otherwise it is advanced construction safety protection hardware measures can not fully guarantee the construction personnel's personal safety. Secondly, the construction unit must strictly examine the construction level of the safety protection measures of the construction unit when tendering the construction unit, incorporate the safety protection measures of the construction unit into the bidding requirements, and urge the construction unit to actively improve its construction safety protection measures. The building construction safety protection measures should be actively introduced into the international advanced construction safety protection facilities. In addition, the construction unit must increase the safety inspection of construction equipment and tools, timely detect the hidden safety hazards in the construction of the construction and eliminate it in time. Hidden dangers to protect the personal safety of construction workers[4].

\subsection{Raise awareness of safety management education of construction units and actively introduce advanced construction project safety management education methods}

The awareness of safety management education of the construction unit directly affects the safety construction awareness of the construction unit and the construction personnel. Therefore, the improvement of the safety management awareness of the construction unit is very important for the safe construction of the construction project. The construction unit should also implement the building construction safety management education responsibility system so that the construction unit will strictly supervise the safe construction of the construction unit. The construction unit is the main supervisor for the construction quality and safety of construction projects. The safety management education awareness of the construction unit will imperceptibly affect the safety construction management education of the construction unit. The construction unit lacks the safety management education of the construction unit and will make it safe for construction. With weak awareness, construction safety management education and safety protection measures will be reduced. This is very unfavorable to the development of safety management education for construction units. Therefore, construction units should pay attention to and actively develop safety management education awareness in order to improve construction. Safety during construction. In addition, the construction unit should also actively learn advanced construction engineering safety management education methods, and continuously innovate safety management education systems adapted to changes in the construction environment to help construction units better carry out building safety management education.

\subsection{Apply safety sensors and Internet technologies to improve safety management education}

The construction administrative department and the safety supervision and management education units at all levels shall promptly establish a safety sensor system platform with the main content of the safety production information system management education, and use high-tech computer databases to construct an early warning mechanism for construction safety accidents. Improve the safety management level at the construction site. By using high-tech remote sensors for safety sensors, you can effectively monitor the real-time conditions on the site, promptly warn about 
problems and mistakes in construction, and at the same time effectively reduce illegal operations at the construction site. To a great extent, construction safety accidents are avoided. On the other hand, the safety sensor system can alleviate the problem of inadequate supervision capacity of administrative departments and safety management education units at all levels, increase work efficiency, and promptly communicate and resolve safety production problems, eradicate safety hazards in advance, and realize "early detection of hidden dangers and early violations of regulations. Correcting and early accident prevention." The safety sensor video surveillance system is also conducive to carrying out on-site rescue work when accidents occur, and enhance the ability to respond to emergency commands. At the same time, it also requires administrative departments and safety management and education units at all levels to speed up scientific research investment and research and development, continuously improve the safety management capacity and level of construction, and use the advanced Internet platform and technology to actively promote the development and improvement of construction safety management education. Progressively realize the informationization and transparency of construction, truly achieve the combination of construction safety information, timely feedback and dynamic supervision, and ultimately achieve the goal of improving the safety management level of construction projects.

\section{Summary}

This article starts from all aspects of construction accidents that are prone to safety accidents, analyzes various factors that are likely to cause construction safety accidents, and proposes some simple suggestions for individuals, involving government regulatory agencies, owners' construction units, supervision units, and construction units. In many aspects of a department, supervisory units and departments at all levels are required to place construction safety at the top of the work.

\section{References}

[1] Marian Drusa,Isık Yilmaz,Marian Marschalko,Eva Coisson,Jaroslaw Rybak,Andrea Segalini. World Multidisciplinary Civil Engineering-Architecture-Urban Planning Symposium - WMCAUS 2017[J]. IOP Conference Series: Materials Science and Engineering, 2017, 245(1).

[2] Dan Russell,Yong K. Cho,Eric Cylwik. Learning Opportunities and Career Implications of Experience with BIM/VDC [J]. Practice Periodical on Structural Design and Construction, 2014, 19 (1).

[3] Symeon Christodoulou. Educating Civil Engineering Professionals of Tomorrow [J]. Journal of Professional Issues in Engineering Education and Practice, 2004, 130(2).

[4] C. Punitha Devi,V. Prasanna Venkatesan,S. Diwahar,G. Shanmugasundaram. A Model for Information Integration Using Service Oriented Architecture [J]. International Journal of Information Engineering and Electronic Business (IJIEEB), 2014, 6(3). 